Article

\title{
Improving Storage Stability and Physicochemical Performance of Styrene-Butadiene-Styrene Asphalt Binder Modified with Nanosilica
}

\author{
Nonde Lushinga ${ }^{1,2} \mathbb{D}$, Liping Cao ${ }^{1, * \mathbb{C}}$, Zejiao Dong ${ }^{1} \mathbb{D}$ and Cyriaque O. Assogba ${ }^{1}(\mathbb{D}$ \\ 1 Department of Road and Railway Engineering, School of Transportation Science and Engineering, \\ Harbin Institute of Technology, Harbin 150090, China; nonde.lushinga@gmail.com (N.L.); \\ hitdzj@hit.edu.cn (Z.D.); assocyr@hotmail.fr (C.O.A.) \\ 2 Department of Construction Economics and Management, School of Built Environment, \\ The Copperbelt University, Kitwe 10101, Zambia \\ * Correspondence: hitclp@hit.edu.cn
}

Received: 18 August 2020; Accepted: 19 October 2020; Published: 28 October 2020

\begin{abstract}
Due to storage stability drawbacks of polymer-modified bitumen (PMB), this study investigated the storage stability and physicochemical performance of Styrene-Butadiene-Styrene (SBS) asphalt binders (herein PMB) modified with Silicone surface-treated nanosilica (SNS). Dosages $0 \%$ (control), $1.5 \%, 3 \%$ and $5 \%$ SNS powder were added to PMB to prepare modified binders. Hot storage, Viscosity, Multiple Stress Creep Recovery (MSCR), Scanning Electron Microscopy (SEM), Fluorescence Microscopy (FM), Linear Amplitude Sweep (LAS), Fourier Transform Infrared (FTIR), and Proton Nuclear Magnetic Resonance $\left({ }^{1} \mathrm{H}-\mathrm{NMR}\right)$ tests were conducted using modified binders. The study found that adding nanosilica powder to PMB improved storage stability, increased viscosity and complex modulus, and reduced rutting of binders. However, this bitumen modification was not beneficial to fatigue cracking. The performance improvement was because of the interaction between the polymer and nanosilica, creating a new polymer-nanosilica network which lowered the dynamics around the SNS particles, thereby reducing phase separation. Further, the Silicone $\mathrm{Si}-\mathrm{O}-\mathrm{Si}$ backbone bond present in SNS modified asphalt binder reduced temperature sensitivity thereby preventing thermal degradation at high storage temperature. Nanosilica modified binders presented well-dispersed nanosilica particles in the asphalt matrix. The modification mechanism was predominantly physical. Overall, the study concluded that nanosilica improves storage stability, rutting, and morphology of PMB binders.
\end{abstract}

Keywords: storage stability; nanosilica; polymer-modified asphalt (PMB); Styrene-Butadiene-Styrene (SBS)

\section{Introduction}

Bitumen or asphalt binder (as it is referred to in North America) is utilized in the production of asphalt mixtures for road construction and industrial application. It is a viscoelastic material whose behavior is temperature and time-dependent. Bitumen behaves as an elastic solid at lower temperatures and high loading frequencies, and as a viscous liquid at higher temperature and lower loading frequency $[1,2]$. This means that bitumen become soft at high temperatures and stiffens at lower temperatures. Further, the performance of asphalt concrete mixtures and their ability to resist pavement distresses, such as fatigue, thermal cracking and rutting, is directly dependent on the mechanical properties of bitumen. Therefore, the poor service life of asphalt pavements is related to bitumen properties [3,4]. To improve the service life and durability of pavements, bitumen should be modified with polymer modifiers [5]. The most widely used modifiers of bitumen is the styrene-butadiene-styrene (SBS) copolymer [6,7]. The styrene component comprises of hard blocks that give bitumen the strength 
to be able to resist permanent deformation, while butadiene are soft blocks that give bitumen flexibility as a result increases resistance to thermal and fatigue cracking potential of bitumen at low and intermediate temperatures, respectively. When SBS is incorporated in asphalt, it undergoes swelling due to the absorption of the aromatic and saturate components of asphalt. The SBS polystyrene components are then evenly distributed in polybutadiene [8]. SBS dosage between 3 and 6\% [9] is known to give the binder the much-needed elastic characteristics [10]. After modification, bitumen forms the continuous phase whereas SBS forms the dispersed phase. Phase inversion increases with increase in the concentration of SBS [11].

Although polymer modification of bitumen generally improves the mechanical properties of modified binders, there are concerns about poor stability during hot storage of PMB in general $\left(140-180^{\circ} \mathrm{C}\right)$. PMB comprises of a phase rich in polymer and a phase rich in bitumen. Phase separation is mostly influenced by density differences between these two phases [12]. Other factors include those that are physicochemical in nature, such as solubility, molecular weight, polarity, microstructure properties and glass transition for bitumen and polymers, which influence compatibility [13]. The instability in the storage of polymer-modified binders at microscopic scale is due to the phase separation process, where polymer modifiers essentially separate from the asphalt binder matrix. This phenomenon can be attributed to different factors such as bitumen type and the nature of the polymer modifiers [14].

To counter these drawbacks, many strategies have been applied. These strategies include the use of antioxidants; sulfur vulcanization; use of functional and reactive polymers, and indeed the use of hydrophobic clay minerals [14]. The use of antioxidants involves the use of materials or additives that retard the oxidative ageing while breaking down hydro peroxides, which are produced during oxidation [15-17]. Even though, they reduce oxidation and consequently inhibit brittleness and possible cracking, which comes with bitumen ageing, they are not so useful in improving storage stability. Moreover, the prices for antioxidants are exorbitant. Sulfur vulcanization, on the other hand, is a chemical process that works in two ways: firstly, polymer molecules are chemically crosslinked, and secondly bitumen and polymers undergo chemical coupling through polysulfide and/or sulfide bonds [18]. The former forms a stable polymer network and the latter directly reduces the separation of the PMB and consequently offers good storage stability. However, there are problems with sulfur vulcanization-such as oxidative ageing and their reliance on unsaturated polymers [19]. Functional and reactive polymers involve incorporating chemical additives into bitumen to get the functionalized bitumen properties capable of improving storage stability. Many however focus on improving compatibility between bitumen and polymer by forming chemical or hydrogen bonds. An example of an additive used for this purpose is Maleic anhydride (MAH); however, recent researchers, such as Su et al. as cited in [20], found that the chemical modification of bitumen with polydimethylsiloxane (PDMS) - silicone oil could also enhance the compatibility of modified asphalt binders and offer good storage stability. Hydrophobic clay minerals can be used in both PMB and base bitumen-for example, kaolinite and montmorillonite (MMT). Previous studies have shown that the application of kaolinite in PMB achieves two main objectives namely: (1) enhancing PMB's storage stability by reducing the difference in density between bitumen and its polymer-modifiers; (2) improving resistance to ageing of PMB with characteristics of the dispersed clay platelets [21].

Beyond the hydrophobic clay minerals, asphalt modification with nanosilica has recently attracted interest among pavement researchers since the advent of nanotechnology. Nanosilica has high chemical purity, high surface area and stability, which makes it ideal for bitumen modification. However, nanomaterials, such as nanosilica, have a tendency to agglomerate because of their small particles and relatively higher surface energies of nanosilica coupled with frequent particle-to-particle interaction [22]. The nanomaterial's propensity to aggregate is a function of its surface properties [23] and the medium in which nanomaterial is dispersed (i.e., viscosity and polarity) $[24,25]$. The nanomaterial's surface properties (for instance surface capping chemistry as well as chemical surface moieties) play a critical role in ensuring that they are dispersed in polar and non-polar solvents [26]. Further, it is worth noting that bitumen is comprised of high molecular hydrocarbons and other derivatives, which make nanomaterials, 
such as nanosilica, have poor dispersion and compatibility [27]. Hence, the nanomaterial's propensity to agglomerate can be readily controlled by modifying their surface characteristics and choosing a solvent like bitumen to enhance dispersion. In the present study, the surface of nanosilica was modified with polydimethylsiloxane (PDMS) or silicone oil thereby making nanosilica highly hydrophobic and more compatible with bitumen. This promotes the adsorbing of light oil in bitumen and adhesion with some components in bitumen thereby changing the original structural form of bitumen and consequently reducing the temperature sensitivity of the bitumen. Dhawale [5] reported that the interactions between SBS polymers and nanosilica were because of the chains in PDMS surface treated nanosilica, which physically entangled with chains from SBS modifier to create a physical polymer-nanosilica network. Because of entanglements, SBS chains are immobilized, which leads to slower movement of molecules around nanosilica, thereby increasing the complex shear modulus. Furthermore, polymers and asphalt are bound together, hence the formed network prevent phase separation of PMB.

Extant literature on nanosilica found that the additive improves anti-aging property, fatigue and rutting of modified binders and mixtures [24]; increases in strength of mixes, temperature stability and resistance to moisture susceptibility [28]; increases in complex shear modulus [29]; increases in viscosity [30]. This research investigates the storage stability and physicochemical properties of SBS binders modified with silicone surface treated nanosilica. The benefit of using polydimethylsiloxane (PDMS) surface treated nanosilica lies in the fact that PDMS modification of the surface of nanosilica reduces the amount of silanol structures found on the surface of nanosilica and alters the functional group on the surface and the structure of the nanosilica at micro-level [5]. As a result, the physical and chemical properties, such as nanosilica adsorption, are altered and the surface free energy (SFE) of the nanosilica filler and the concept of agglomeration between particles are lowered. In addition, PDMS has high hydrophobicity owing to its size and organic content. This high hydrophobicity on the surface of nanosilica promote an even distribution of particles in similar medium, such as bitumen. Moreover, the physical chain of the PDMS surface treated nanosilica enhances physical interaction between bitumen and SBS. Further, it is a well-known fact that temperature is elevated up to $200^{\circ} \mathrm{C}$ during hot storage and processing of bitumen, therefore the bond energy in PDMS surface treated nanosilica is higher than $\mathrm{C}=\mathrm{C}$ bonds due to the existence of $\mathrm{Si}-\mathrm{O}-\mathrm{Si}$ bonds, which can withstand thermal degradation at high temperatures.

\section{Research Objective and Significance}

During hot storage of polymer-modified bitumen (PMB), polymers tend to separate from the asphalt binders due to viscosity and density differences as well as incompatibility between the two components, which float and agglomerate at the top of the modified binders [31-33]. The instability of PMB motivates pavement engineers and researchers to find new materials to improve the performance of PMB. On the other hand, the utilization of Aerosil R202 fumed silica (nanosilica) in bitumen modification remains largely unexplored [5]. However, in quest to explore new and novel materials to mitigate storage instability concerns and phase separation of PMB, this study evaluated the potential use of Aerosil R202 fumed silica (herein nanosilica) to improve storage stability, physical and chemical properties of PMB. The performance indicators for storage stability and rheological characterization included Storage stability based on comparison of complex shear modulus between the tube test bottom and top portions of the samples. Further, Brookfield viscosity, rutting based on the Multiple Stress Creep Recovery (MSCR) test, resistance to fatigue cracking based on Linear Amplitude Sweep (LAS) test, chemical characterization employing Fourier Transform Infrared (FTIR) and Proton Nuclear Magnetic Resonance $\left({ }^{1} \mathrm{H}-\mathrm{NMR}\right)$ tests were conducted on prepared samples. Morphological, compatibility and microstructure changes in nanosilica-modified binders were studied by Scanning Electron Microscopy (SEM) and Fluorescence Microscopy (FM) respectively. Thin-film oven test (TFOT) aged samples were utilized on rheological tests. 
One of the benefits of using nanomaterials is the low-cost of producing the material as well as its superior performance [11]. Researchers, such as Yu et al. [34] found that modifying nanomaterial with polymers is cost-effective because both the amount of polymers and nanomaterials needed in composite blends is reduced while the compatibility of polymers with bitumen is increased. In this regard, the current study is significant because it seeks to promote the utilization of cost effective and sustainable construction materials to mitigate storage and phase separation concerns of PMB, which are currently the major drawbacks in the application of PMB. The study is also important because nanosilica generally improves the mechanical properties of asphalt binders, which may lead to the construction of more durable and high performing asphalt pavements. It is the authors' considered view that the novelty of the paper lies in expanding the potential application of Aerosil R202 nanosilica in bitumen modification to address the aforementioned drawbacks of PMB.

\section{Research Methodologies}

\subsection{Materials}

\subsubsection{Asphaltic Binder}

The bitumen utilized in this study was SBS modified asphalt (SBS-ID) standard, herein referred to as polymer modified bitumen (PMB), and was obtained from Maoming Lusheng Asphalt Co., Ltd. in China with fundamental properties given in Table 1. PMB was utilized as control group.

Table 1. Fundamental physical properties of Polymer-modified bitumen.

\begin{tabular}{ccc}
\hline Test Items & Values & Criteria \\
\hline Softening point $\left(\right.$ Ring and Ball) ${ }^{\circ} \mathrm{C}$ & 68 & $\geq 50$ \\
Ductility $\left(5^{\circ} \mathrm{C}, 5 \mathrm{~cm} / \mathrm{min}\right) \mathrm{cm}$ & 26 & $\geq 20$ \\
Needle Penetration $(0.1 \mathrm{~mm})$ at $25^{\circ} \mathrm{C}$ & 55 & $40-60$ \\
Density $\mathrm{g} / \mathrm{cm}$ & 1.03 & - \\
Dynamic Viscosity $(\mathrm{Pa} \cdot \mathrm{s})$ at $135{ }^{\circ} \mathrm{C}$ & 1.79 & $\leq 3$ \\
Flash point ${ }^{\circ} \mathrm{C}$ & 290 & $\geq 230$ \\
Solubility $\%$ & 99.6 & $\geq 99$ \\
Softening point $\left(163{ }^{\circ} \mathrm{C}, 48 \mathrm{~h}\right){ }^{\circ} \mathrm{C}$ & 1.75 & $\leq 2.5$ \\
Elastic recovery $\left(25{ }^{\circ} \mathrm{C}\right) \%$ & 83 & $\geq 75$ \\
Mass loss $\%$ & 0.5 & $\leq 1.0$ \\
Penetration ratio $\%$ & 71 & $\geq 65$ \\
Ductility $(5 \%, 5 \mathrm{~cm} / \mathrm{min}) \mathrm{cm}$ & 16 & $\geq 15$ \\
\hline
\end{tabular}

Note: Data in Table 1 was obtained from the manufacturer.

\subsubsection{Nanosilica}

Nanoparticles of silicon dioxide $\left(\mathrm{SiO}_{2}\right)$ are often termed as Nanosilica. Silica precursors are used to produce this inorganic material. For example, silicon dioxide can be processed chemically from rice husk ash or synthetized from silica fume [30]. Nanosilica particles have been used to provide reinforcement to elastomers and this area of study has attracted interest among pavement engineers and researchers. Nano materials generally have a low cost of production but higher performance [35]. The Aerosil R202 fumed silica, herein nanosilica (shown in Figure 1), was employed in this study). This material was sourced from Evonik Specialty Chemicals Co. Ltd. in Shanghai, China and its properties are presented in Table 2. 


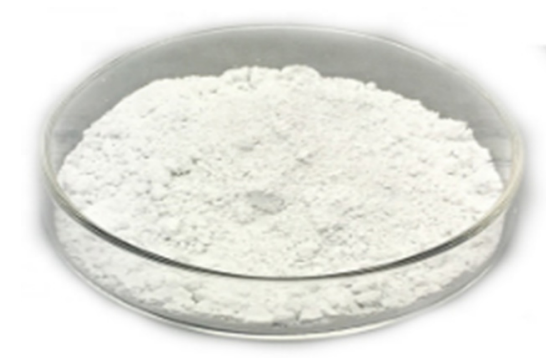

Figure 1. Nanosilica powder utilized herein.

Table 2. The basic properties of Nanosilica.

\begin{tabular}{cccccc}
\hline Type & $\mathrm{SiO}_{2}(\%)$ & Carbon (\%) & Particle Size $(\mathrm{nm})$ & Density $\mathbf{g} / \mathrm{cm}^{3}$ & Specific Surface Area $\left(\mathrm{m}^{2} / \mathbf{g}\right)$ \\
\hline AEROSIL R202 fumed silica & $\geq 99.8$ & $3.5-5$ & 14 & 0.04 & $80-120$ \\
\hline & Note: Data in Table 2 was obtained from the manufacturer.
\end{tabular}

\subsubsection{Preparation of Nanosilica-Modified Asphalt}

A method proposed by Yusoff et al. [36] was employed in the preparation of nanosilica/SBS modified binders. Nanosilica particles were incorporated into the PMB control binders at concentrations of $0 \%$ (control), $1.5 \%, 3 \%$ and $5 \%$ (by weight of the asphalt) and sheared at $160{ }^{\circ} \mathrm{C}$ and $1500 \mathrm{rpm}$ for one hour. The experimental flow chart is given in Figure 2.

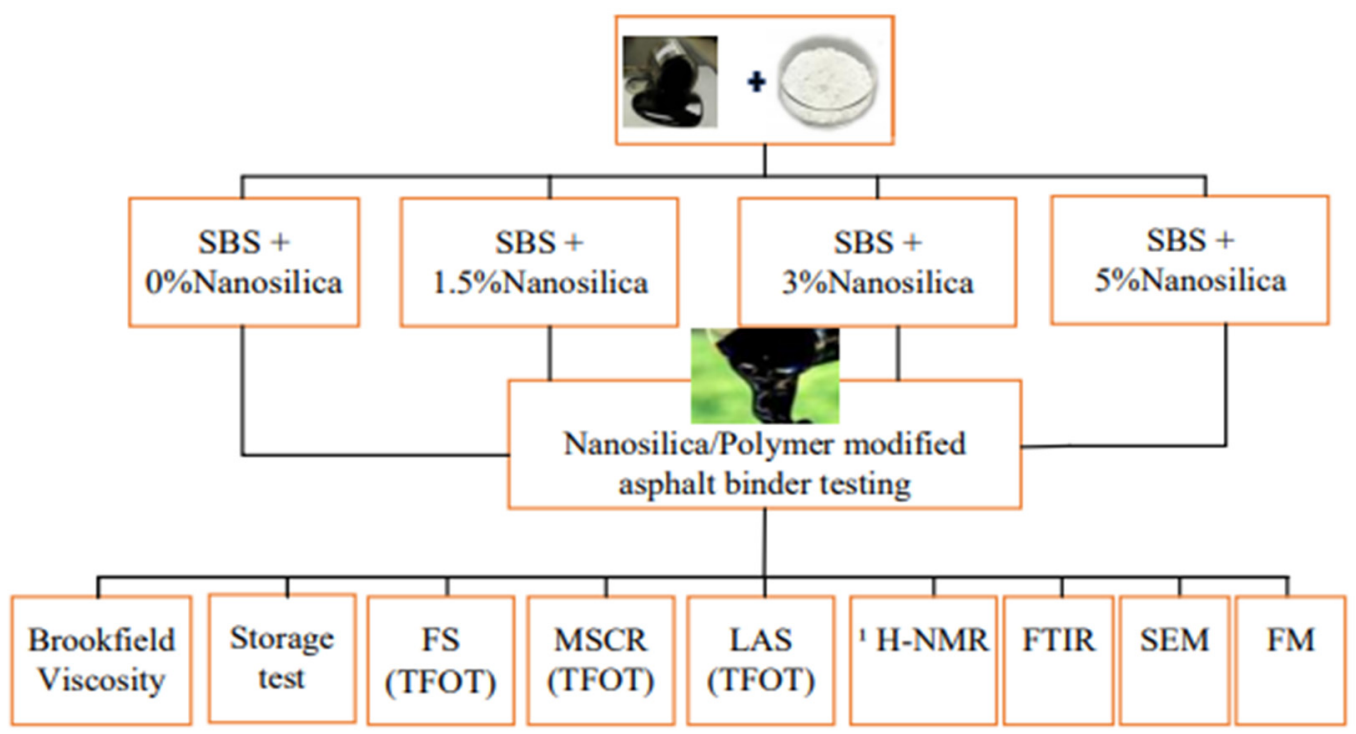

Figure 2. Experimental flow chart.

\subsection{Experimental Design}

\subsubsection{Fourier Transform Infrared (FTIR) Test}

One of the accurate ways to fingerprint asphalt is FTIR testing. The FTIR technique can also be used to identify polymer additives in asphalt in order to ensure quality control and quality assurance [37]. Herein, the nanosilica and SBS polymer additives in bitumen were identified using FTIR technique. In order to achieve this purpose, the Thermo Scientific Nicolet iS 50 instrument (manufactured by Thermo Fisher Scientific in Massachusetts, USA) was utilized. The sample preparation consisted of heating the modified bitumen to flow at $160{ }^{\circ} \mathrm{C}$ and placing it on glass slides. The test was performed in the range between from 4000 to $400 \mathrm{~cm}^{-1}$ wave numbers. 


\subsubsection{Nuclear Magnetic Resonance (NRM)}

Proton Nuclear Magnetic Resonance $\left({ }^{1} \mathrm{H}-\mathrm{NMR}\right)$ is a powerful tool for characterizing bitumen. ${ }^{1} \mathrm{H}-\mathrm{NMR}$ allows for investigations in solid and liquids and is able to quantify constituents in a material in a single spectrum. Herein the ${ }^{1} \mathrm{H}-\mathrm{NMR}$ spectra test was conducted using a high-resolution Bruker Avance, spectrometer manufactured by Bruker Rheinstette in Germany. Proton NMR spectra were employed in which modified bitumen samples were dissolved in deuterated chloroform ( $\mathrm{CDCl} 3)$.

\subsubsection{Fluorescence Microscopy (FM)}

This test was employed to analyze the morphology and microstructure changes in modified binders due to the differences in fluorescence between SBS control binders and those modified with nanosilica. The fluorescence microscopy DVM5000 HD purchased from Leica Microsystems (Buffalo Grove, IL, USA) was used to evaluate the morphological characteristics of the proposed asphalt binder. During preparation, hot asphalt binder (about $160^{\circ} \mathrm{C}$ ) was poured on glass slide mold. To achieve a thin surface film, the sample was initially heated to $160^{\circ} \mathrm{C}$ in the oven for $5 \mathrm{~min}$ and followed by cooling period.

\subsubsection{Scanning Electron Microscopy (SEM)}

Microstructure changes and dispersion of nanosilica in SBS/Nanosilica modified asphalt binder were analyzed using SEM image observation. The S-3000N Scanning Electron Microscope manufactured by Hitachi Ltd. in Tokyo, Japan with magnification of 200 and 500 times was employed. Before SEM observation, asphalt and nanosilica samples were pre-treated using gold-sputtering.

\subsubsection{Viscosity Testing}

The fluid's ability to flow can be measured by Rotational viscometer (RV). In the present study, $\mathrm{RV}$ was utilized to measure the viscosity of SBS/nanosilica modified bitumen at $175^{\circ} \mathrm{C}$ in accordance with AASHTO TP48. Spindles of different sizes were utilized to determine viscosity.

\subsubsection{Frequency Sweep (FS) Test}

The FS image test was performed, utilizing the state of the art DHR-2 manufactured by TA Instruments (New Castle, Delaware, USA). The DSR rheometer measures phase angle and complex shear modulus of bitumen after applying sinusoidal stress. High temperatures ranging from $50^{\circ} \mathrm{C}$ to $75^{\circ} \mathrm{C}$ and frequencies ranging from 0.1 to $50 \mathrm{~Hz}$ were considered using a $25 \mathrm{~mm}$ diameter parallel plate and a $1 \mathrm{~mm}$ hole setting out. The tests were conducted in conformity with AASHTO TP5. Prior to FS test, thin film oven test (TFOT) aging test was conducted on samples, in accordance with AASHTO T-240.

\subsubsection{Multiple Stress Creep Recovery (MSCR) Test}

MSCR test gives better prediction for rutting for base and modified binders as compared to Superpave rutting binder specification. In this test one creep cycle consisted of loading time of $1 \mathrm{~s}$ and preceded by recovery time of $9 \mathrm{~s}$ as guided by ASTM D 4705. The cycle was repeated 10 times at stress levels of $0.1 \mathrm{kPa}$ another 10 times of $3.2 \mathrm{kPa}$. Beyond the repeated creep test, modulus at $10 \mathrm{rad} / \mathrm{s}$ was recorded during thermal equilibrium. The resistance to permanent deformation is governed by non-recoverable creep compliance $J_{n r}$ at $3.2 \mathrm{kPa}$ stress level. The repeated creep test was performed at $64^{\circ} \mathrm{C}$ on TFOT aged samples using DHR-2 manufactured by TA Instruments (New Castle, DE, USA). Equation (1) was used to calculate the non-recoverable compliance (Jnr).

$$
J_{n r}=\frac{\gamma_{n}-\gamma_{0}}{\tau}
$$


where $\gamma_{o}=$ shear strain (cycle start); $\tau=$ creep loading stress and $\gamma_{n}=$ strain (non-recoverable) obtained after 9 -s recovery.

\subsubsection{Linear Amplitude Sweep (LAS) Test}

To accurately measure the fatigue cracking potential of SBS/nanosilica modified bitumen, the Linear Amplitude Sweep (LAS) test was employed using DHR-2 manufactured by TA Instruments (New Castle, DE, USA) in which the specimen is subjected to cyclic loading with increasing amplitudes. This test uses a DSR instrument utilizing a standard $8 \mathrm{~mm}$ diameter parallel plate and $0.2 \mathrm{~cm}$ gap between the plates. The test followed the two step approaches in tandem with AASHTO TP 101-14-i.e., frequency sweep and amplitude sweep with strain load of $0.1 \%$ and between 0.2 and $30 \mathrm{~Hz}$ frequency range. The second step precedes the first step where samples are loaded using strain sweep utilizing $10 \mathrm{~Hz}$ frequency of oscillation shear loading. At chosen temperatures, strain amplitude with continuous loading cycles was increased from 0 to $30 \%$ continuous loading cycles to induce fatigue cracking damage. The resistance to fatigue is then determined from frequency sweep and amplitude-sweep test results using the simplified viscoelastic continuum damage (S-VECD) model presented elsewhere by Xu et al. [38].

\subsubsection{Storage Stability Tests}

The hot storage tube test (ASTM D7131) was used to analyze the storage stability of binders. Exactly $50 \mathrm{~g}$ of prepared Nanosilica/SBS asphalt samples were poured into an aluminum tube $(140 \mathrm{~mm}$ high and $25 \mathrm{~mm}$ diameter) sourced from local suppliers in China. Then, the samples were maintained in the vertical vessel of an oven for $48 \mathrm{~h}$ at $163^{\circ} \mathrm{C}$. Thereafter, the samples were cooled in the refrigerator for $4 \mathrm{~h}$ after which three equal portions or parts were cut from the tube. The bottom and top parts of the modified bitumen samples were then separated and subjected to DSR testing to determine the complex shear modulus and subsequently the degree of separation or segregation index (SI) as described elsewhere [39].

\section{Results and Discussion}

This section presents the results of tests performed on Nanosilica/polymer modified asphalt specimens.

\subsection{Chemical Characterization of Nanosilica/PMB Binders}

\subsubsection{Fourier Transform Infrared (FTIR)}

Functional groups are important in characterizing materials in the chemical process. The characteristic bands in the absorption spectrum of the transmitted IR radiation can be used to identify the chemical bond. By comparing and analyzing the functional groups of the asphalt binders before and after modification, determination on whether some chemical reactions or physical process had occurred during the composite modification would be made [40]. In general, the infrared spectrum shown in Figure 3a comprises wavenumbers ranging from $4000 \mathrm{~cm}^{-1}$ to $400 \mathrm{~cm}^{-1}$. This is further split in two regions namely functional group region (FGR) and fingerprint regions (FPR) as shown in enlarged Figure $3 b, c$ respectively. The wave numbers for FGR range from $4000 \mathrm{~cm}^{-1}$ to $1330 \mathrm{~cm}^{-1}$ whereas for FPR, wavenumbers range from $1330 \mathrm{~cm}^{-1}$ to $400 \mathrm{~cm}^{-1}$. FGR is used to identify the functional group and hence in the determination of the material structure. Figure 3a presents FTIR spectra of PMB before and after addition of nanosilica. The Absorption peaks 2921 and $2850 \mathrm{~cm}^{-1}$ correspond to $\mathrm{CH} 2$ and $\mathrm{CH} 3$ Stretching (Alkanes) in bitumen, whereas $\mathrm{C}=\mathrm{C}$ stretching-aromatics correspond to IR peaks at $1600 \mathrm{~cm}^{-1}$. The absorbance peaks at 1467 and 1378 represent $\mathrm{CH} 3$ asymmetric and symmetric deformation-alkanes, respectively [40]. For nanosilica powder, the absorption peak at $1050 \mathrm{~cm}^{-1}$ corresponds to the $\mathrm{Si}-\mathrm{O}-\mathrm{Si}$ bond, which is the silicone backbone for silica modified surface; however, this peak shifts towards the $1100 \mathrm{~cm}^{-1}$ wavelength when nanosilica is incorporated into the 
binder. This shift indicates that bitumen interacted with the siloxane bond of the nanosilica powder to produce SBS/nanosilica-modified bitumen [5]. According to Daily et al. [37], the two IR peaks around $966 \mathrm{~cm}^{-1}$, as well as at $700 \mathrm{~cm}^{-1}$, correspond to SBS butadiene segments $\mathrm{C}=\mathrm{C}$ bonds and SBS styrene segments $\mathrm{C}-\mathrm{H}$ bending which show the presence of SBS in modified asphalt binders. As can be seen in Figure $3 a$ and its enlarged functional group region presented in Figure $3 b, c$, the characteristic peaks for polymers remain unaltered after adding the nanosilica powder to PMB. This illustrate the physical interaction between polymers and nanosilica in bitumen. The absorption maxima for SBS/Nanosilica modified asphalt is presented in Table 3. Fini et al. [19] observed that the surface of pure nanosilica has silanols, which promotes the formation of hydrogen bonds with asphaltenes in bitumen. However, such prepositions are not likely in this study, since the surface of the nanosilica (Aerosil R202) was treated with silicone oil or PDMS, which is methyl terminated. Chemical reactions between surface silanol groups of PDMS functional ends.

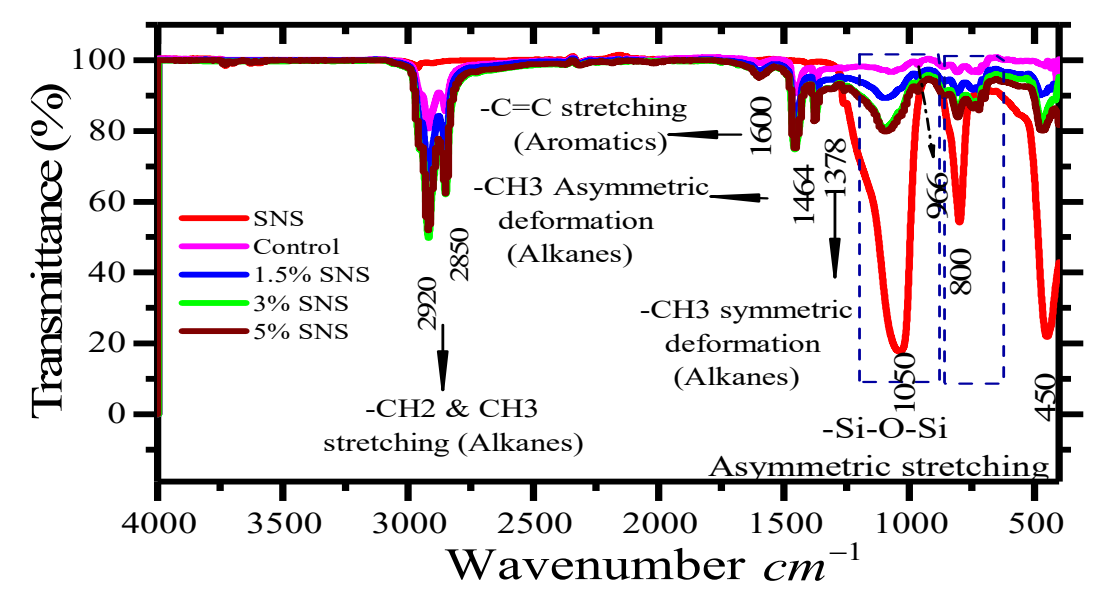

(a)

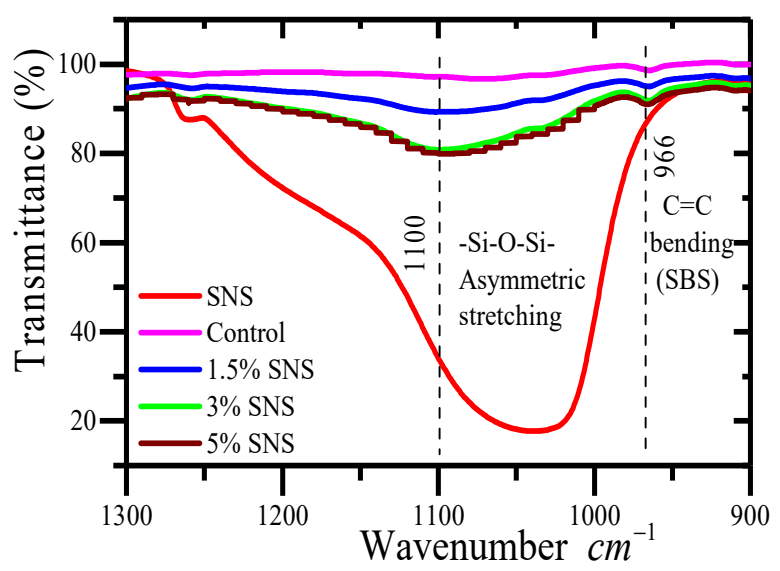

(b)

Figure 3. Cont. 


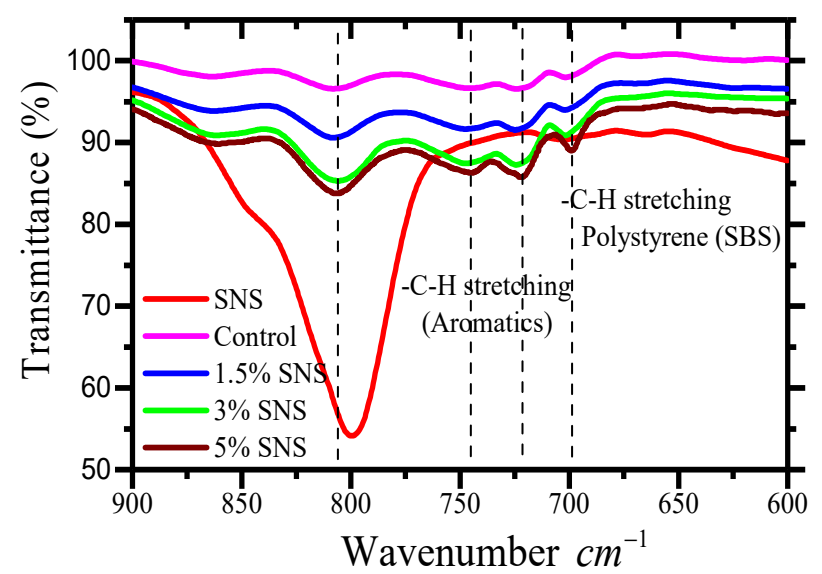

(c)

Figure 3. FTIR spectra of Nanosilica/polymer-modified asphalt; major functional group (a), enlarged functional group region (FGR) (b) and enlarged fingerprinting region (FPR) (c).

Table 3. FT-IR spectral data of Nanosilica/polymer—modified asphalt [37,40].

\begin{tabular}{|c|c|c|c|}
\hline Wavenumber $\mathrm{cm}^{-1}$ & Functional Group & $\begin{array}{l}\text { Wavenumber } \mathrm{cm}^{-1} \\
\text { from Literature }\end{array}$ & Species \\
\hline 2920,2850 & -CH2 \& -CH3 Stretching (Alkanes) & 2920,2850 & Aliphatic \\
\hline 1600 & $-\mathrm{C}=\mathrm{C}$ stretching (Aromatics) & 1600 & - \\
\hline 1464,1378 & - $\mathrm{CH} 3$ Asymmetric deformation (Alkanes) & 1464,1378 & Aliphatic \\
\hline 1100 & -Si-O-Si Asymmetric stretching & $1050-1150$ & - \\
\hline 966 & $-\mathrm{C}=\mathrm{C}$ bending (SBS) & $965-970$ & Butadiene block (SBS) \\
\hline 749 & $\begin{array}{c}-\mathrm{C}-\mathrm{H} \text { trans disubstituted }-\mathrm{CH}=\mathrm{CH} \\
\text { (butadiene block) }\end{array}$ & $900-600$ & - \\
\hline 805 & -Si-O Symmetric bending (silanol) & $796-805$ & - \\
\hline 724 & $-(\mathrm{CH} 2) n$ & $724-722$ & Aliphatic chain \\
\hline 700 & $-\mathrm{C}-\mathrm{H}$ bending in styrene (SBS) & 700 & Polystyrene block (SBS) \\
\hline 467 & -Si-O bond rocking & $438-475$ & - \\
\hline
\end{tabular}

\subsubsection{Nuclear Magnetic Resonance $\left({ }^{1} \mathrm{H}-\mathrm{NMR}\right)$ Spectroscopy}

Bitumen fractions determine the bitumen mechanical properties and characteristics. NMR spectroscopy has been found to be a practically efficient and reliable technique for complex material characterization, such as bitumen [41]. Herein, the distribution and relative amount of the aliphatic and aromatic hydrogen protons were investigated with a single ${ }^{1} \mathrm{H}-\mathrm{NMR}$ spectrum using MestReNova (Mnova) (version 14.1.2, Mestrelab Research Chemistry Solutions, Santiago de Compostela, Spain). Mnova is the latest Nuclear Magnetic Resonance software for data processing, visualization, simulation, prediction, presentation and analysis. The spectra of analyzed bitumen is given in Figure 4. Typical ${ }^{1} \mathrm{H}-\mathrm{NMR}$ signal positions commonly used for data interpretation are reported in Table 4. If the protons associated to the heteroatoms are neglected, the NMR spectrum is characterized by five types of proton groups: aromatic protons $\left(H_{a r} ; 6-9 \mathrm{ppm}\right)$ olefinic protons ( $\left.H_{\text {ol }} ; 4-6 \mathrm{ppm}\right)$, alpha-alky protons $\left(H_{\alpha} ; 1-2 \mathrm{ppm}\right)$ primarily the methylene protons which are $\beta$ or farther from the aromatic ring $\left(H_{\beta} ; 1-2 \mathrm{ppm}\right)$ and the methylene protons in the $\gamma$ position or farther from the aromatic ring $\left(H_{\gamma} ; 0.5-1 \mathrm{ppm}\right)$. Therefore, the intense peaks observed in Figure 4 can be correlated with ${ }^{1} \mathrm{H}-\mathrm{NMR}$ signal positions in Table 4. 


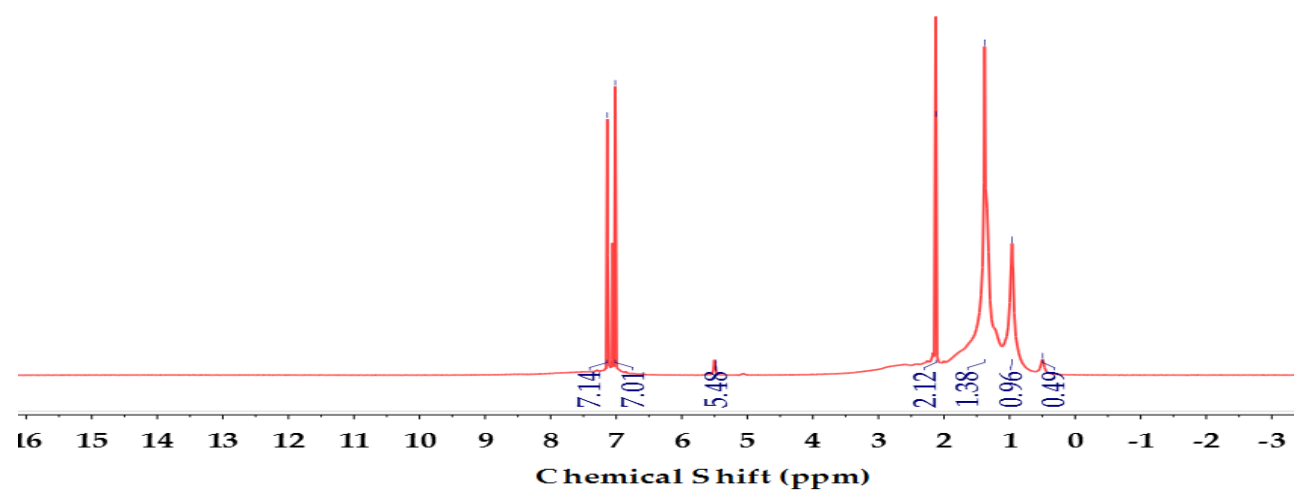

(a)

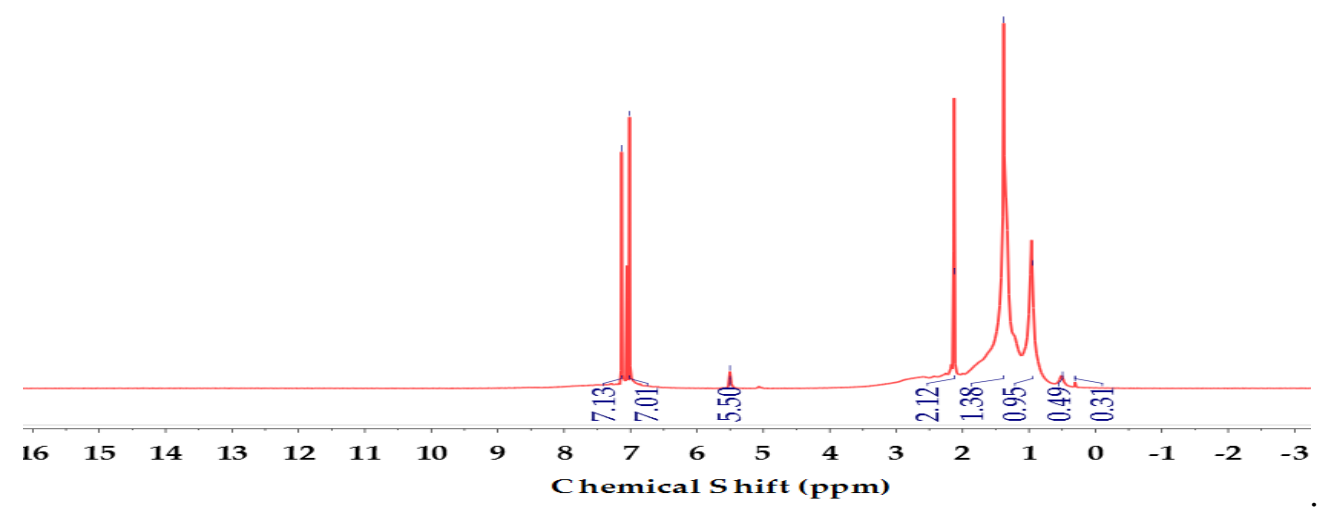

(b)

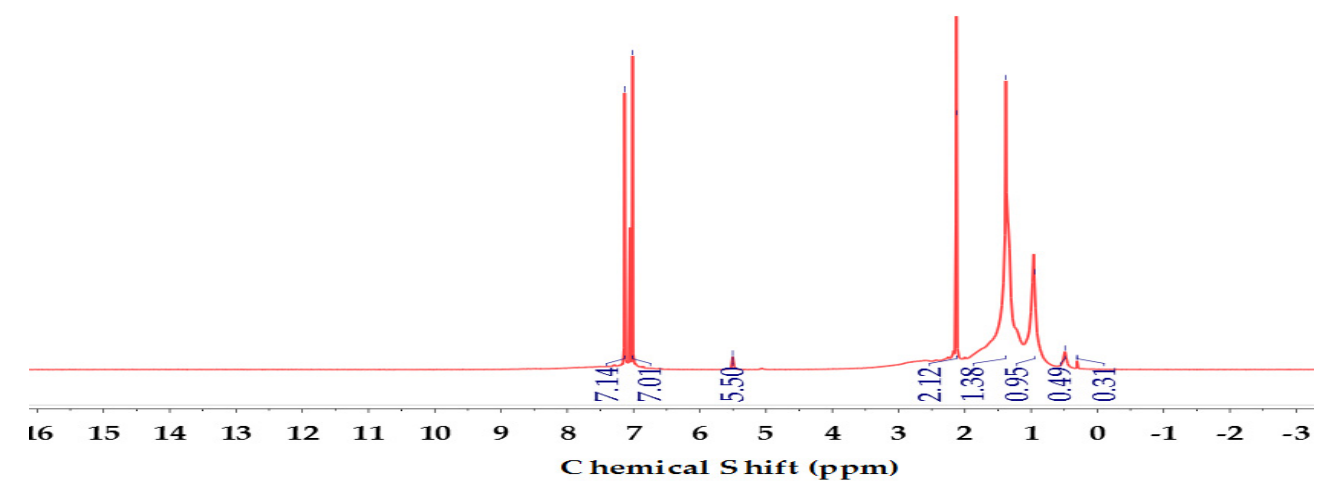

(c)

Figure 4. Cont. 


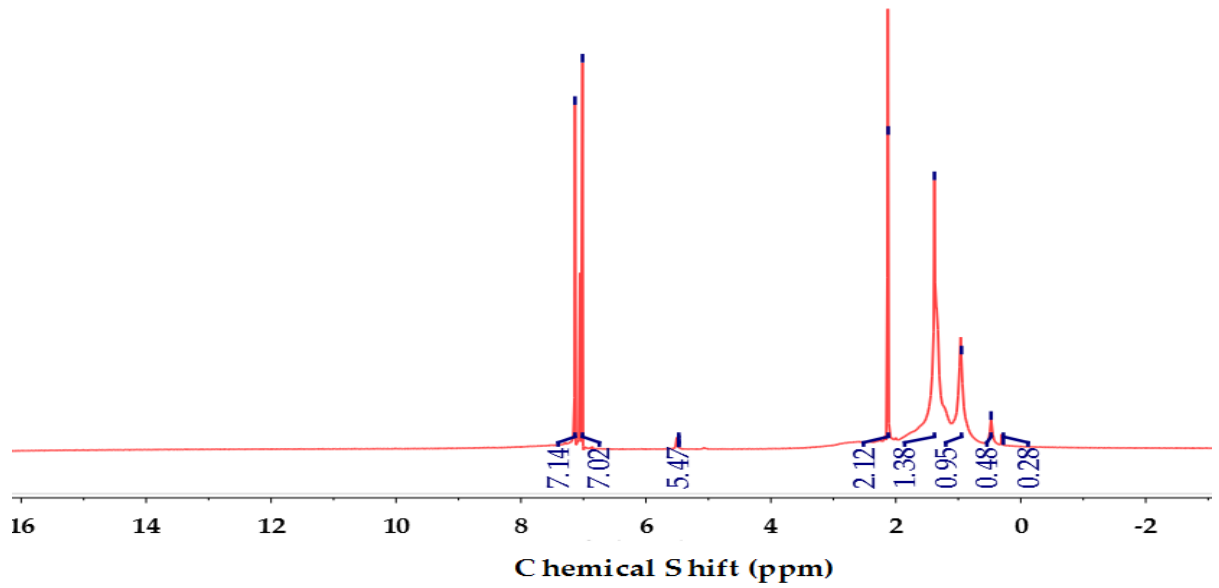

(d)

Figure 4. ${ }^{1} \mathrm{H}$ NMR spectra of Nanosilica/Polymer-modified asphalt. Control binder (a); $1.5 \%$ SNS (b); $3 \%$ SNS (c); and $5 \%$ SNS (d).

Table 4. ${ }^{1} \mathrm{H}-\mathrm{NMR}$ Chemical shifts (ppm) and corresponding hydrogen types [41,42].

\begin{tabular}{ccc}
\hline Parameter & Chemical Shift $\delta$ (ppm) & Hydrogen Type \\
\hline$H_{a r}$ & $6.0-9.0$ & Aromatic hydrogen \\
$H_{o l}$ & $4.0-6.0$ & Olefinic hydrogen \\
$H_{\alpha}$ & $2.0-4.0$ & Aliphatic Hydrogen on $C_{\alpha}$ to aromatic rings \\
$H_{\beta}$ & $1.0-2.0$ & Aliphatic Hydrogen on $C_{\beta}$ and the $\mathrm{CH}_{2}$ beyond the $C_{\beta}$ to aromatic rings \\
$H_{\gamma}$ & $0.5-1.0$ & Aliphatic Hydrogen on $C_{\gamma}$ and the $\mathrm{CH}_{3}$ beyond the $C_{\gamma}$ to aromatic rings \\
\hline
\end{tabular}

The regions selected for each spectrum were integrated and normalized to get the fractional proton distributions directly from the integration curve. Table 5 presents the fractional proton distribution SBS/nanosilica modified asphalt from ${ }^{1} \mathrm{H}-\mathrm{NMR}$ spectra. The results show that the area corresponding to the aromatic zone is nearly the same for the SBS control binder $(8.89 \%)$ and $1.5 \%$ SNS $(8.13 \%)$ samples. For samples with 3\% SNS and 5\% SNS, the distributions of aromatic protons were much higher-i.e., $11.84 \%$ and $12.82 \%$, respectively. On the other hand, the higher percentages of aliphatic protons were observed in the SBS control $(91.09 \%)$ and $1.5 \%$ SNS $(91.85 \%)$ but significantly reduced with an increase in nanosilica content, as can be seen for 3\% SNS (88.49) and 5\% SNS (83.16\%) samples, respectively.

Table 5. Fractional proton distribution of SBS/Nanosilica-modified asphalt obtained from H-NMR spectra.

\begin{tabular}{ccccc}
\hline \multirow{2}{*}{ Bitumen } & \multicolumn{4}{c}{ Hydrogen Distribution $\pm \mathbf{0 . 0 5}$} \\
\cline { 2 - 5 } & $\boldsymbol{H}_{\boldsymbol{a r}}$ & $\boldsymbol{H}_{\boldsymbol{o l}}$ & $\boldsymbol{H}_{\boldsymbol{\beta}}$ & $\boldsymbol{H}_{\boldsymbol{\gamma}}$ \\
\hline SBS-Control & 8.89 & 10.24 & 76.92 & 3.93 \\
SBS + 1.5\% SNS & 8.13 & 8.57 & 72.26 & 11.02 \\
SBS + 3.0\% SNS & 11.84 & 7.92 & 67.11 & 13.46 \\
SBS + 5.0\% SNS & 12.82 & 9.74 & 61.49 & 15.93 \\
\hline
\end{tabular}

According to Soenen et al. [43], larger aromatic structures in bitumen give rise to improved interactions and can be correlated with the elastic behavior of bitumen at elevated temperature and longer loading times. On the other hand, smaller aromatic structures inform more of the elastic behavior of bitumen at low temperature and short loading times. In addition to aromatic interactions, natural wax inherent in bitumen can, upon crystallization, also induce increased elastic effects, especially at low frequencies. In this regard, it was the view of authors that addition of nanosilica to SBS modified binders 
increases the aromatic content in bitumen, which can be beneficial to the improvement of elastic behavior of bitumen and consequently higher resistance to permanent deformation. Further, higher aromatic content of bitumen improves interaction, hence justifying the excellent dispersion of nanosilica in the SBS modified binder matrix observed in fluorescence microscopy.

\subsection{Morphological and Microstructure Properties}

\subsubsection{Fluorescence Microscopy (FM)}

The compatibility and state of dispersion of silicone surface treated nanosilica in SBS modified bitumen was studied by FM. Compatibility describes the level of interactions between the asphalt and polymer. An image obtained using FM can effectively show the compatibility of polymers in bitumen and can help predict the stability of the modified binder. The morphological arrangement of the asphaltene-rich polymer (ARP) and the polymer-rich phase (PRP) in modified binder is dependent on polymer/asphalt compatibility [39]. In the present FM images, bitumen appears dark while polymer and nanosilica particles appear brighter.

Figure 5a shows the FM image SBS control binders in which the polymer distribution of SBS particles in asphalt indicates an intimate mixing. Figure 5b,d shows the FM image of well distributed nanosilica particles in SBS modified bitumen and with higher dispersity. This indicates that silicone surface treated nanosilica has high compatibility with asphalt.

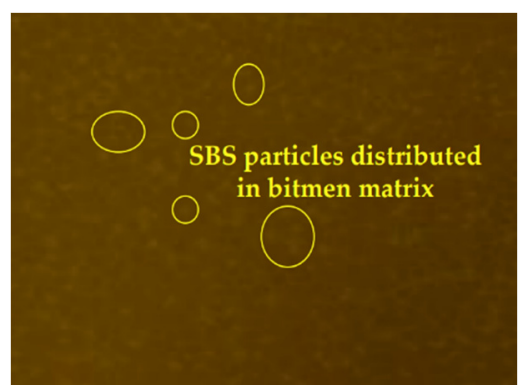

(a)

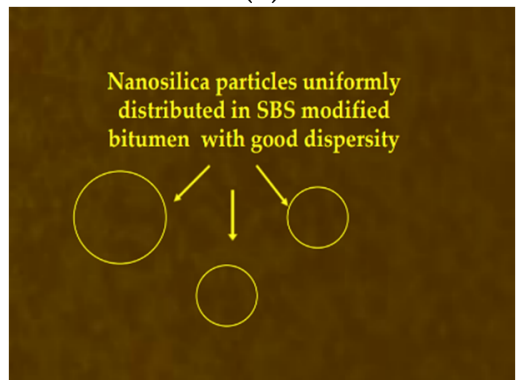

(c)

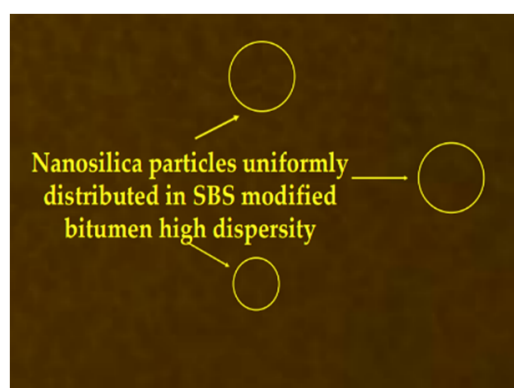

(b)

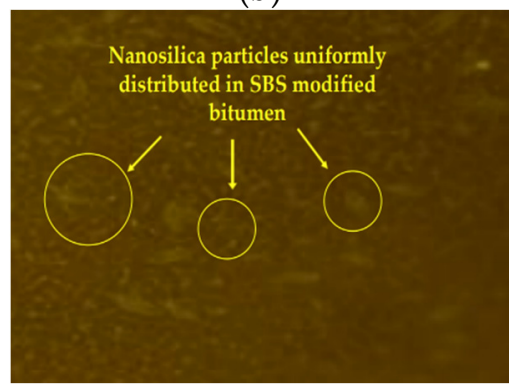

(d)

Figure 5. Fluorescence microscopy images of Nanosilica/SBS modified binders. (a) SBS without nanosilica; (b) SBS + 1.5\% nanosilica; (c) SBS + 3\% nanosilica; (d) SBS + 5\% nanosilica.

\subsubsection{Scanning Electron Microscopy}

The performance of asphalt binder is affected by not only the compatibility between asphalt and SBS particles but also the morphology and structure of modified asphalt binder [39]. The SEM images of nanosilica modified asphalt are helpful to understand the microstructure change in modified asphalt, as well as the physical dispersion of nanosilica particles [36,43]. Figure 6 shows the SEM image of nanosilica powder, while Figure 7a-d shows the microstructure and morphology of SBS/nanosilica modified asphalt binder, which changed significantly compared to the control asphalt binder. The SEM images of nanosilica modified asphalt binder present the well-dispersed nanosilica particles in the asphalt matrix. The surface of the nanosilica group reacts with the asphalt binder, and the size of 
nanosilica group becomes smaller. The new structure of the nanosilica modified asphalt binder is formed. The nanosilica dispersion in the asphalt binder may be helpful for the modulus improvement of nanosilica modified asphalt mixture as the nanosilica particles become small and bond together [43].

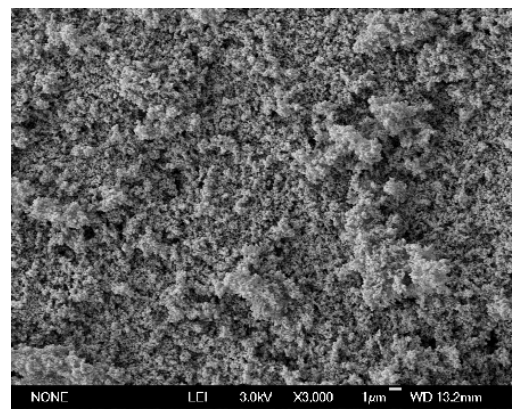

Figure 6. SEM image of Nanosilica powder at 3000× magnification.

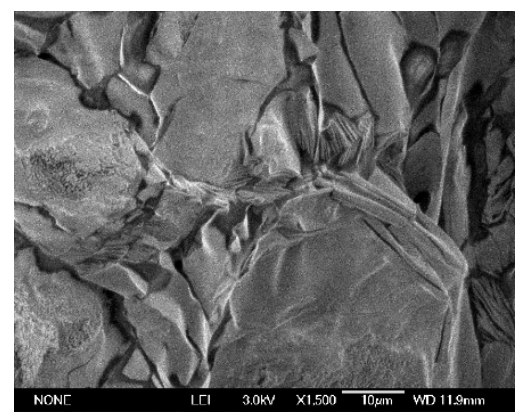

(a)

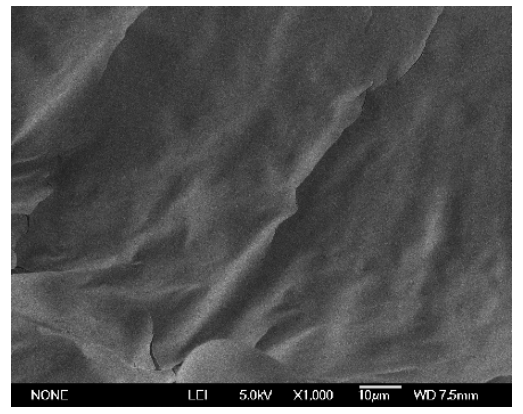

(c)

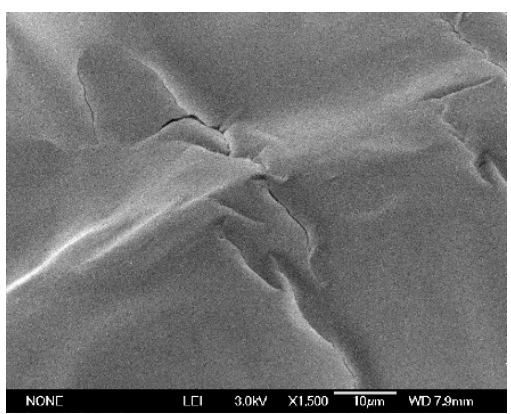

(b)

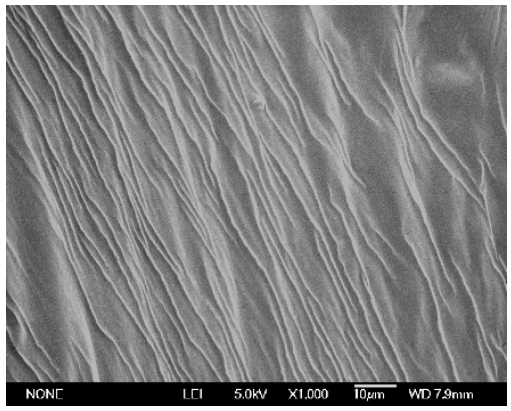

(d)

Figure 7. SEM images of Nanosilica/PMB modified binders. (a) SBS-Control at 300 $\times$ magnification; (b) SBS + 1.5\% nanosilica at 300 $\times$ magnification; (c) SBS + 3\% nanosilica at 500 $\times$ magnification; (d) SBS + $5 \%$ nanosilica at $500 \times$ magnification.

\subsection{Intermediate Temperature Fatigue Cracking}

In this study, LAS tests were conducted on TFOT aged samples at $25^{\circ} \mathrm{C}$ and analysis of results was based on S-VECD theory. Figure 8a presents damage curves, which is plotted as material integrity (C) (i.e., value of $\left|G^{*}\right|$ ) versus material damage integrity (S) and determined in conformity with AASHTO TP 101, 2014. As can be seen, initial material integrity decreases with an increase in material damage, but the material integrity decrease is more rapid for the nanosilica-modified binders. It was established that the damage curves of the SBS control binders were generally similar with those modified with nanosilica; however, the nanosilica binders had softer curves. Table 6 presents fatigue curves fitting parameters from the S-VECD model. Bessa et al. [15] observed that the higher parameter $A$ indicates increased resistance of the material to fatigue cracking. Therefore, since the SBS control binders have higher $A$ parameter it has better material damage resistance. Furthermore, fatigue curves shown in 
Figure $8 \mathrm{~b}$ revealed that SBS/nanosilica modified-binders have generally lower resistance to fatigue damage. The fatigue life of SBS decreases with the addition of nanosilica. This phenomenon is attributed to the stiffening nature of nanosilica on SBS binders, which reduces flexibility.

Table 6. Fatigue curves fitting parameters in LAS test.

\begin{tabular}{cccc}
\hline \multirow{2}{*}{ Binder } & \multicolumn{2}{c}{ Fatigue Curves Coefficient } & \multirow{2}{*}{ Summed Error } \\
\cline { 2 - 3 } & $\mathbf{A}$ & $\mathbf{B}$ & \\
\hline Control & $9.077 \times 10^{5}$ & -3.021 & 0.007 \\
$1.5 \%$ SNS & $7.062 \times 10^{5}$ & -3.104 & 0.009 \\
$3 \%$ SNS & $7.362 \times 10^{5}$ & -3.118 & 0.009 \\
$5 \%$ SNS & $7.360 \times 10^{5}$ & -3.131 & 0.003 \\
\hline
\end{tabular}

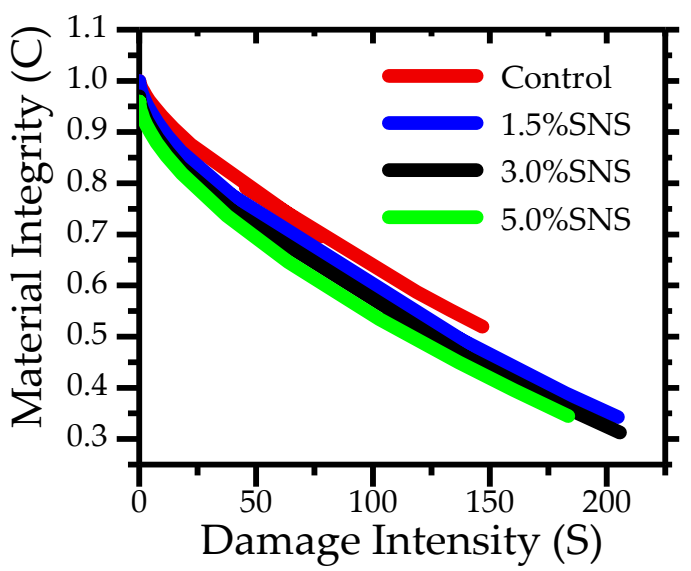

(a)

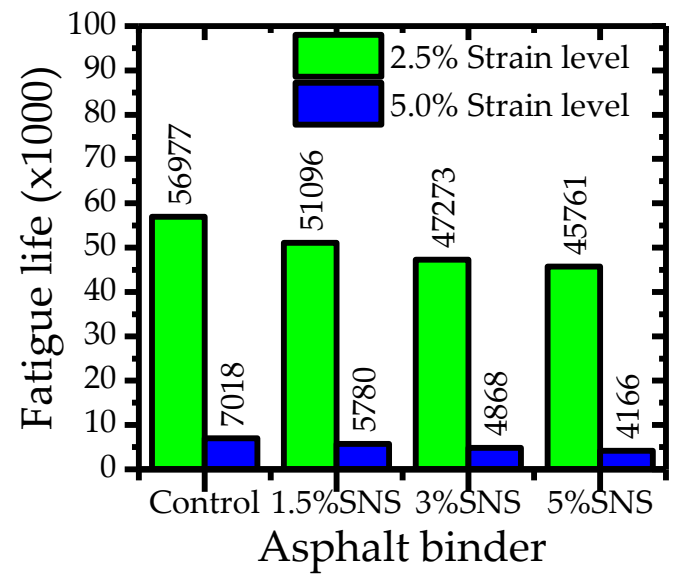

(b)

Figure 8. LAS test (a) damage characteristic curves (b) fatigue life (Nf) of PMB/Nanosilica modified asphalt binders.

\subsection{High Temperature Permanent Deformation}

Figure 9 presents results of the MSCR test. Laboratory results showed that incorporating Nanosilica powder to SBS increases resistance to permanent deformation by decreasing the permanent strain also known as non-recoverable creep compliance- $J_{n r}$. The increased rutting resistance can be attributed to different factors such as reduction in temperature sensitivity of the bitumen due to addition of PDMS surface treated nanaosilica and the formation of new polymer-nanosilica physical network. The modification of the surface of nanosilica with PDMS promotes compatibility between bitumen and nanosilica and also the adsorbing of light oil in bitumen and adhesion with some components in bitumen thereby changing the original structural form of bitumen and consequently reducing the temperature sensitivity of the bitumen. Reduced temperature sensitivity of bitumen increases resistance to permanent deformation. On the other hand, the interactions between SBS polymers and nanosilica makes the chains in PDMS surface treated nanosilica, to physically entangle with chains from SBS modifier thereby creating a physical polymer-nanosilica network. Because of this entanglements, SBS chains are immobilized, which leads to slower dynamics movement of molecules around nanosilica, thereby increasing the complex shear modulus. The increase in complex modulus was beneficial to reducing rutting or the permanent strain in the binder. The difference in creep compliance-Diff $J_{n r}$ between two stress levels $(3.2 \mathrm{kPa}$ and $0.1 \mathrm{kPa})$ for all binders was less than $75 \%$, which indicated that the binders were all within the Superpave specification limit. Further, it was established that control binders could support standard traffic designated as $\mathrm{S}$, while the nanosilica modified binders could support heavy traffic levels, designated as $\mathrm{H}$ (Table 7). Overall, the results 
demonstrate that nanosilica improves high temperature permanent deformation by increasing the stiffness and elasticity of the binders. This result agrees with previous studies by Yusoff et al. [36].

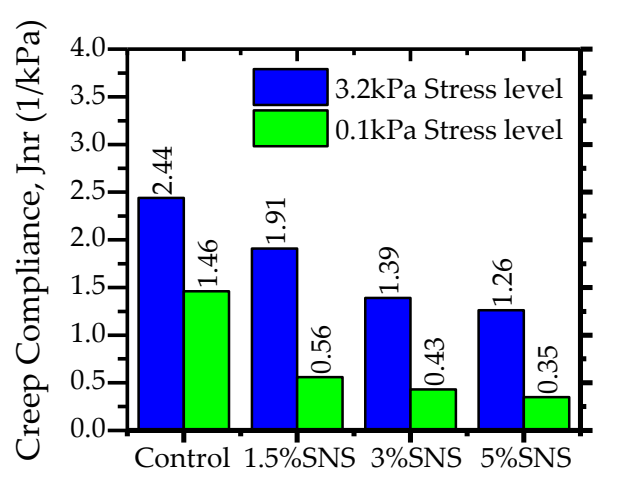

Nanosilica/PMB asphalt binders

(a)

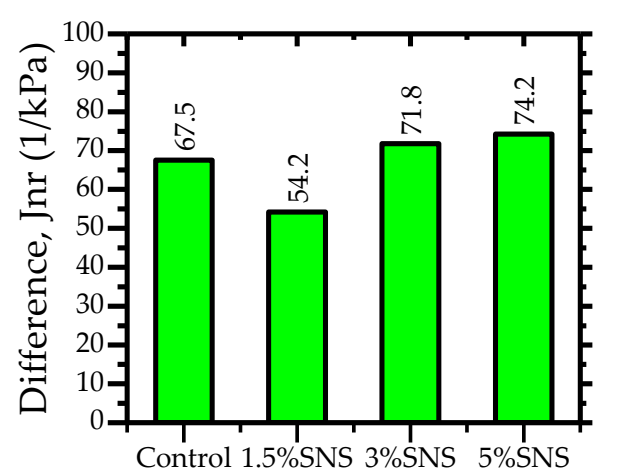

Nanosilica / PMB asphalt binder

(b)

Figure 9. MSCR (a) creep compliance-Jnr (b) Difference-Jnr.

Table 7. Traffic level definition and MSCR parameters [20].

\begin{tabular}{cccc}
\hline Grade & Max. Jnr 3.2 (k/Pa) & Max. Jnr Diff (\%) & Traffic Level \\
\hline S & $<4$ & 75 & Standard \\
$\mathrm{H}$ & $<2$ & 75 & Heavy \\
$\mathrm{V}$ & $<1$ & 75 & Very heavy \\
$\mathrm{E}$ & $<0.5$ & 75 & Extremely heavy \\
\hline
\end{tabular}

\subsection{Workability Analysis}

Figure 10 presents results of rotary viscosity for SBS and nanosilica modified asphalt binders. It is evident that the addition of nanosilica to SBS increases viscosity values. As the content of nanosilica increases, so did the viscosity of the modified binders. At the temperature of $135^{\circ} \mathrm{C}$, the viscosity of all binders were lower than 3.0 Pa.s, which satisfied the Superpave standard specification. This result was consistent with previous work by Ezzat et al. [30], Alhamali et al. [44], and Santagata et al. [45]. The resistance to permanent deformation of bitumen may be partly due to increased viscosity, which results in a higher stiffness at elevated temperatures.

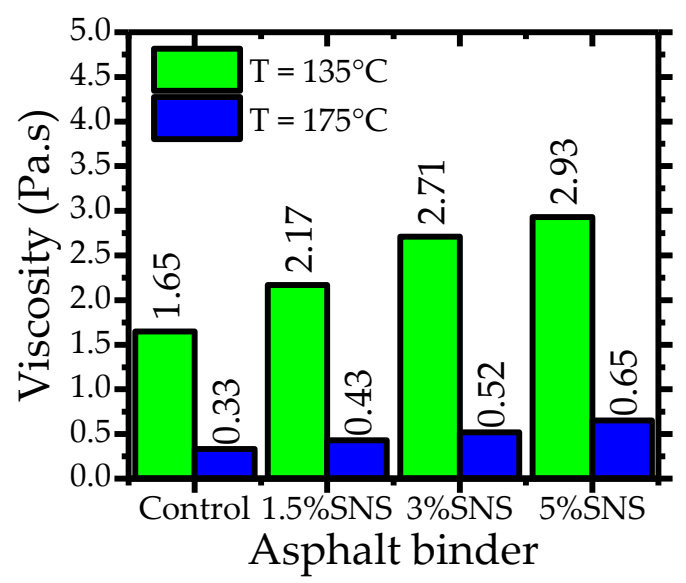

Figure 10. Rotary viscosity of PMB and Nanosilica modified asphalt. 


\subsection{Storage Stability Analysis}

The prime objective of introducing nanosilica to SBS modified asphalt was to improve the storage stability of the polymer-modified bitumen, which is a major problem during high temperature application. The ASTM D5892-00 standard was used to determine the storage stability of binders where complex shear modulus of samples from the top and bottom of tube after 48-h storage experiment at $163{ }^{\circ} \mathrm{C}$ were compared. As described in Section 3.2.7, high temperatures ranging from $50{ }^{\circ} \mathrm{C}$ to $75^{\circ} \mathrm{C}$, and frequencies ranging from 0.1 to $50 \mathrm{~Hz}$ were performed using a $25 \mathrm{~mm}$ diameter parallel plate and a $1 \mathrm{~mm}$ hole setting out. The Christensen Anderson Marasteanu (CAM) model, and the Williams-Landel-Ferry (WLF) shift factors, represented by Equations (2) and (3), were utilized to fit the complex modulus dataset and develop master curves, as given below and described elsewhere $[40,46]$.

$$
\begin{gathered}
G *=G_{e}^{*}+\frac{G_{g}^{*}-G_{e}^{*}}{\left[1+\left(f_{c} / f^{\prime}\right)^{k}\right]^{m_{c} / k}} \\
\log \alpha_{T}=-\frac{C_{1}\left(T-T_{r e f}\right)}{C_{2}+\left(T-T_{r e f}\right)}
\end{gathered}
$$

where $G *=$ complex modulus at reduced frequency $f^{\prime}$, while $G_{e}^{*}=$ equilibrium complex modulus when frequency is infinitely close to zero, often assumed 0 for asphalt binders. $G_{g}^{*}=$ complex modulus at glass transition when frequency is close to infinity. $k$ and $m c$ are shape parameters. $\alpha_{T}=$ shift factors which can be obtained by fitting William-Landrel-Ferry (WLF) function. $T_{r e f}=$ standard reference temperature, $C_{1}$ and $C_{2}$ are the model parameters.

The hot storage stability of modified bitumen was then evaluated by way of subjecting samples in top and bottom parts of the storage tube to DSR testing. By comparing the complex shear modulus of the aforementioned samples, the hot storage stability was determined. The rationale of this experiment is that any settlement of undissolved filler or polymer particles in asphalt in the aluminum test tube would obviously lead to some changes in the complex shear modulus. As an alternative to the conventional softening point and penetration, it is an increasingly common practice to evaluate the two fractions in terms of their rheological properties.

Figure 11 presents master curves for top and bottom samples. The results revealed that the gap between the top and bottom decreased with the incorporation of nanosilica, which indicated improved storage stability. The results further revealed that the sample with $1.5 \%$ SNS had the best storage stability, as attested by the master curves. Moreover, the complex modulus increased with the addition of the nanosilica dosage. This is due to the entanglements of surface PDMS groups of nanosilica with SBS chains which create a physical network and thus slow the dynamics around the nanosilica, which reduces phase separation. According to Sabaraya et al. [47], nano materials that tend to disperse relatively better in the surrogate environment-i.e., retain their nanoscale identity better relative to others-also tend to show a relatively better performance in terms of rheological properties. The difference in complex shear modulus between the storage tube top and bottom part samples reduces with the addition of nanosilica. 


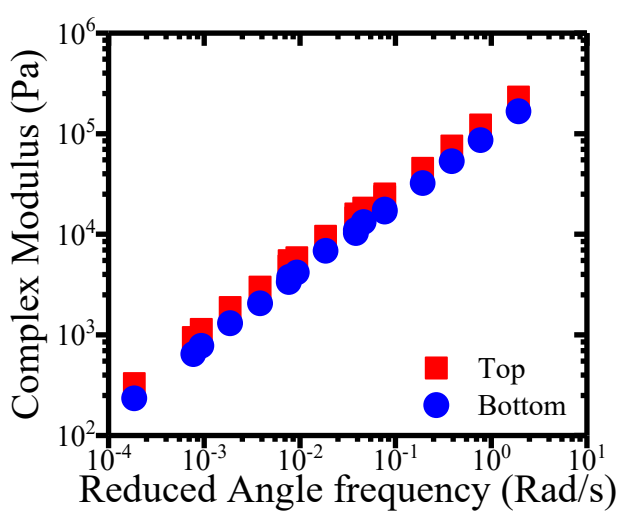

(a)

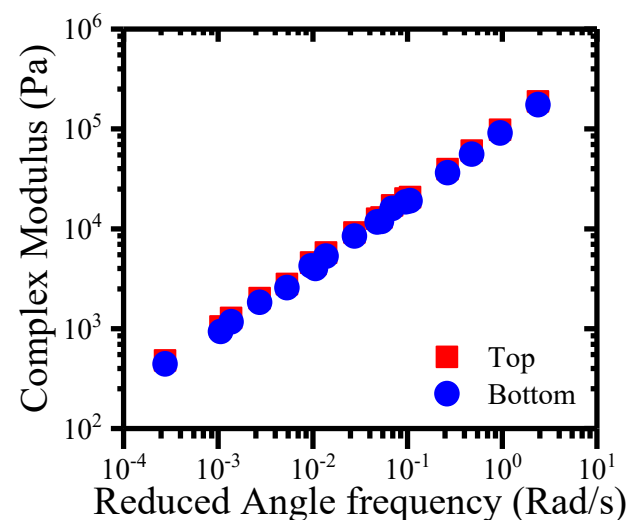

(c)

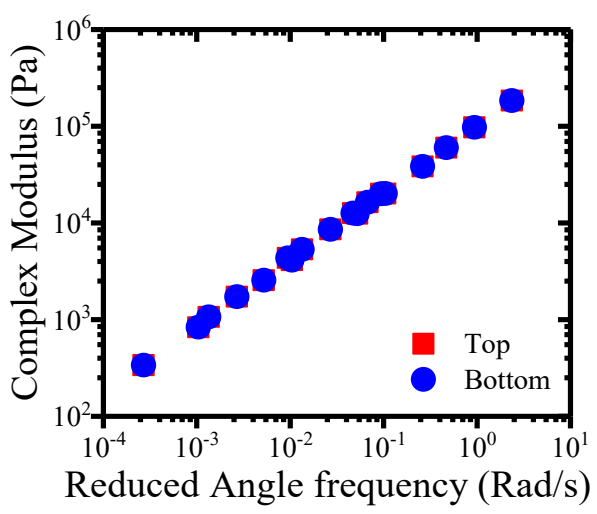

(b)

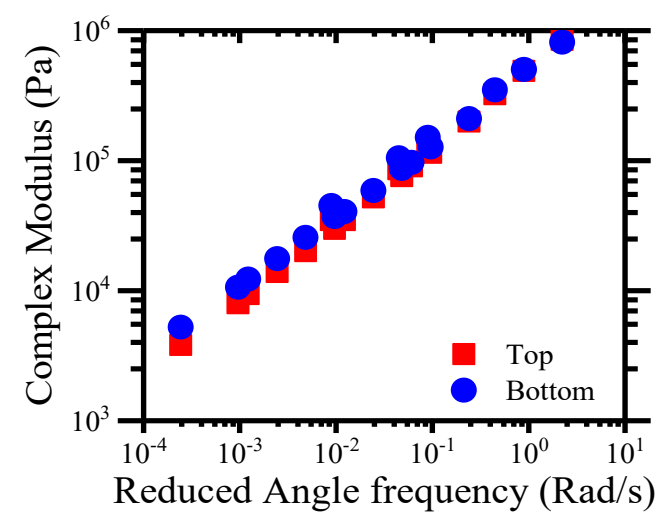

(d)

Figure 11. Master curves for top and bottom samples (a) PMB-Control; (b) PMB+1.5\%SNS; (c) PMB+3\%SNS; (d) PMB+5\%SNS.

Ultimately, the ratio $\left(\left|G_{*}\right| / \operatorname{Sin} \delta\right)$ (where $\delta=$ phase angle and $\left|G^{*}\right|=$ complex modulus), taken from SHRP specifications, was used to calculate segregation Index (SI) according to Equation (4).

$$
\% \text { Seperation }=\frac{(|G *| / \operatorname{Sin} \delta)_{\max }-(|G *| / \operatorname{Sin} \delta)_{\operatorname{avg}}}{(|G *| / \operatorname{Sin} \delta)_{\operatorname{avg}}}
$$

where $(|G *| / \operatorname{Sin} \delta)_{\max }$ represent the rutting parameter with highest values of either the top or bottom section of the tube, whereas $(|G *| / \operatorname{Sin} \delta)_{\text {avg }}$ represent rutting parameter with the average value of both sections.

From Figure 12, the segregation index (SI) results for nanosilica-modified binders were generally lower than for the SBS control binders. Further, binders with $1.5 \%$ SNS had the lowest SI, which is an indication of good compatibility and storage stability. During hot storage, bitumen is subjected to high temperature, such as $200{ }^{\circ} \mathrm{C}$. At this elevated temperature, the silicone treated surface groups are thermally stable due to the silicone backbone ( $\mathrm{Si}-\mathrm{O}-\mathrm{Si}$ ) that would withstand more thermal degradation than an organic backbone, such as $\mathrm{C}=\mathrm{C}$ bonds, even if polystyrene in SBS is highly hydrophobic. 


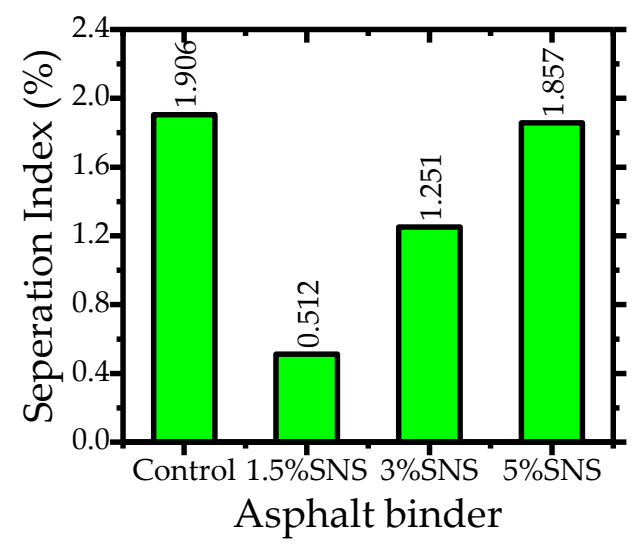

Figure 12. Segregation index of Nanosilica/PMB binder.

\section{Conclusions}

This paper investigated the storage as well as physical and chemical properties of polymer modified asphalt-PMB (herein SBS asphalt) modified with nanosilica. The influence of the nanosilica dosage on properties of PMB binders, such as chemical and microstructure morphology, storage stability, viscosity, rutting, and fatigue resistance were compared. Based on rigorous experiments, and results thereof, the following conclusions were made:

- Chemical analysis through FTIR tests established that an absorption peak $1050 \mathrm{~cm}^{-1}$ corresponded to the $\mathrm{Si-O}-\mathrm{Si}$ bond in nanosilica powder; however, this peak shifted to higher wavelength of $1100 \mathrm{~cm}^{-1}$ when nanosilica was added to the asphalt binder. The two peaks around $966 \mathrm{~cm}^{-1}$ and $700 \mathrm{~cm}^{-1}$ corresponded to an SBS butadiene segments $\mathrm{C}=\mathrm{C}$ bonds and SBS styrene segments $\mathrm{C}-\mathrm{H}$ bending, which showed the presence of SBS in the modified asphalt binders. This shift indicates that asphalt interacted with the siloxane bond of the nanosilica powder to produce nanosilica modified asphalt binder.

- The ${ }^{1} \mathrm{H}$ NMR spectra results revealed that adding nanosilica to SBS modified asphalt increased the aromatic content of bitumen. Larger aromatic structures in bitumen give rise to improved interactions and can be correlated with the elastic behavior of bitumen at elevated temperature and longer loading times, whereas smaller aromatic structures inform more of the elastic behavior of bitumen at low temperature and short loading times. Hence the study concluded that the higher aromatic content in SBS/nanosilica modified bitumen can be beneficial to improving rutting resistance of bitumen.

- FM and SEM tests results led to the conclusion that nanosilica particles improved dispersion in the asphalt matrix. The improved dispersion is attributed to the surface modification of nanosilica with PDMS silicone oil, which is highly hydrophobic and makes nanosilica more compatible with asphalt. This is beneficial for adsorbing light oil in asphalt or bonding with some components in the asphalt. Hence, the original structural form of the asphalt was changed, and the temperature sensitivity of the asphalt after the modification was lowered, which improves the rutting resistance of asphalt binders. Further, a new polymer-nanosilica network structure was formed that binds white nanosilica particles and asphalt together. The improved dispersion is beneficial to modulus improvement. Another school of thought is that the increased aromatic content in bitumen found in the H-NMR test, would result into an improved interaction between bitumen and polymers, hence good dispersion.

- By comparing the complex modulus of the asphalt sample from the bottom and top portions of the hot storage tube, the addition of the nanosilica to PMB decreased the gap between top and bottom, thereby improving the storage stability. This was due to surface PDMS groups' entanglements with the nanosilica and SBS chains, which created a physical network, thus slowing the movements around nanosilica particles that prevent phase separation. Further, the bond energy in PDMS 
surface treated nanosilica is higher than $\mathrm{C}=\mathrm{C}$ bonds due to the existence of $\mathrm{Si}-\mathrm{O}-\mathrm{Si}$ bonds which can withstand thermal degradation at high temperatures. However, it should be mentioned that the storage stability was better when a low amount of $1.5 \%$ SNS was used and that increasing the amount of SNS resulted in less stability.

- The addition of nanosilica powder to PMB binder's increases resistance to permanent deformation by decreasing the permanent strain also known as non-recoverable creep compliance- $J_{n r}$ (i.e., the residual strain in a specimen after creep and recoverable cycle divided by the applied stress). This is mainly due to increased binder stiffness and reduced temperature susceptibility of bitumen. Further, the higher aromatic content SBS/nanosilica modified bitumen has improved elastic properties during high temperature and longer loading times hence is beneficial to rutting resistance.

- The viscosity of bitumen increased due to the addition of nanosilica. The resistance to the permanent deformation of bitumen may be partly due to increased viscosity, which results in a higher stiffness at elevated temperatures. However, the viscosity of all binders in this study met Superpave specification limits of less than $3.0 \mathrm{~Pa} \cdot \mathrm{s}$.

- On the other hand, nanosilica was not beneficial to fatigue cracking improvement in PMB binders. Results revealed that the addition of nanosilica increases damage intensity and decreases fatigue life. This is attributed to the stiffening effect of nanosilica on PMB binders that reduces its flexibility at intermediate temperature.

The findings from this research highlight the significance of bitumen modification with nanosilica powder to improve storage stability and physicochemical properties. Further, the study has noted the importance of surface modification for nanosilica to improve dispersion in bitumen. In this regard, PDMS silicone oil surface-treated nanosilica was utilized. The chains in PDMS surface-treated nanosilica physically entangled with chains from SBS modifier to create a physical polymer-nanosilica network. Because of this physical entanglements, SBS chains were immobilized, which leads to slower movements around nanosilica, thereby reducing phase separation.

Besides, the good results obtained, the study had one limitation. Low temperature cracking performance was not undertaken. However, it is worth noting that PDMS silicone oil chemical treatment on the surface of nanosilica guarantees the hydrophobia of the product, which can improve, among others, the water-resistance of moisture sensitive formulations. In this regard, future research can consider moisture susceptibility of bitumen modified with silicone surface treated nanosilica.

Author Contributions: Conceptualization, L.C.; data curation, N.L. and C.O.A.; formal analysis, N.L. and C.O.A.; funding acquisition, L.C. and Z.D.; investigation, N.L. and C.O.A.; project administration, Z.D.; resources, Z.D.; supervision, L.C. and Z.D.; validation, L.C. and Z.D.; visualization, C.O.A. All authors have read and agreed to the published version of the manuscript.

Funding: The National Key R\&R Program of China (Grant Number: 2018YBI1600100) and the National Natural Science Foundation of China with Grant no. 51978219 funded this research.

Acknowledgments: The authors particularly wish to thank Tao Zhou, Ao Li and Weijun Wang of Harbin Institute of Technology for diagram visualization, and assistance in laboratory testing respectively. Special thanks to Ephraim Zulu of the Copperbelt University in Zambia for his excellent language editing.

Conflicts of Interest: The authors declare no conflict of interest.

\section{References}

1. Peters, S.J.; Rushing, T.S.; Landis, E.N.; Cummins, T.K. Nanocellulose and microcellulose fibers for concrete. Transp. Res. Rec. J. Transp. Res. Board 2010, 2142, 25-28. [CrossRef]

2. Yildirim, Y. Polymer modified asphalt binders. Constr. Build. Mater. 2007, 21, 66-72. [CrossRef] 
3. Shafabakhsh, G.H.; Ani, O.J. Experimental investigation of effect of Nano TiO2/SiO2 modified bitumen on the rutting and fatigue performance of asphalt mixtures containing steel slag aggregates. Constr. Build. Mater. 2015, 98, 692-702. [CrossRef]

4. Singh, M.; Kumar, P.; Maurya, M.R. Strength characteristics of SBS modified asphalt mixes with various aggregates. Constr. Build. Mater. 2013, 41, 815-823. [CrossRef]

5. Dhawale, A.P. Polymer-Nanoparticle-Modification of Bitumen Using Styrene-Butadiene-Styrene (SBS) Triblock Copolymer, Crumb Rubber (Cr) and Fumed Nanosilica. MSc Dissertation, Cornel University, New York, NY, USA, 2017. [CrossRef]

6. Nciri, N.; Kim, N.; Cho, N. New insights into the effects of styrene-butadiene-styrene polymer modifier on the structure, properties, and performance of asphalt binder: The case of AP-5 asphalt and solvent deasphalting pitch. Mater. Chem. Phys. 2017, 193, 477-495. [CrossRef]

7. Shen, J.; Amirkhanian, S.; Xiao, F.; Tang, B. Influence of surface area and size of crumb rubber on high temperature properties of crumb rubber modified binders. Constr. Build. Mater. 2009, 23, 304-310. [CrossRef]

8. Polacco, G.; Muscente, A.; Biondi, D.; Santini, S. Effect of composition on the properties of SEBS modified asphalts. Eur. Polym. J. 2006, 42, 1113-1121. [CrossRef]

9. Kumar, K.; Singh, A.; Maity, S.K.; Srivastava, M.; Sahai, M.; Singh, R.K.; Garg, M.O. Rheological studies of performance grade bitumens prepared by blending elastomeric SBS (styrene butadiene styrene) co-polymer in base bitumens. J. Ind. Eng. Chem. 2016, 44, 112-117. [CrossRef]

10. Zapién-Castillo, S.; Rivera-Armenta, J.L.; Chávez-Cinco, M.Y.; Salazar-Cruz, B.A.; Mendoza-Martínez, A.M. Physical and rheological properties of asphalt modified with SEBS/montmorillonite nanocomposite. Constr. Build. Mater. 2016, 106, 349-356. [CrossRef]

11. Zhu, J.; Birgisson, B.; Kringos, N. Polymer modification of bitumen: Advances and challenges. Eur. Polym. J. 2014, 54, 18-38. [CrossRef]

12. Zhu, J.; Lu, X.; Kringos, N. Experimental investigation on storage stability and phase separation behaviour of polymer-modified bitumen. Int. J. Pavement Eng. 2018, 19, 832-841. [CrossRef]

13. Zhu, J.; Kringos, N. Towards the development of a viscoelastic model for phase separation in polymer-modified bitumen. Road Mater. Pavement Des. 2015, 16, 39-49. [CrossRef]

14. Wang, H.; Liu, X.; Erkens, S.; Skarpas, A. Experimental characterization of storage stability of crumb rubber modified bitumen with warm-mix additives. Constr. Build. Mater. 2020, 249, 118840. [CrossRef]

15. Bessa, I.S.; Vasconcelos, K.L.; Branco, V.T.F.C.; Bernucci, L.L.B. Fatigue resistance of asphalt binders and the correlation with asphalt mixture behaviour. Road Mater. Pavement Des. 2019, 20, S695-S709. [CrossRef]

16. Dessouky, S.; Contreras, D.; Sanchez, J.; Papagiannakis, A.T.; Abbas, A. Influence of hindered phenol additives on the rheology of aged polymer-modified bitumen. Constr. Build. Mater. 2013, 38, 214-223. [CrossRef]

17. Ouyang, C.; Wang, S.; Zhang, Y.; Zhang, Y. Improving the aging resistance of styrene-butadiene-styrene tri-block copolymer modified asphalt by addition of antioxidants. Polym. Degrad. Stab. 2006, 91, 795-804. [CrossRef]

18. Larsen, D.O.; Alessandrini, J.L.; Bosch, A.; Cortizo, M.S. Micro-structural and rheological characteristics of SBS-asphalt blends during their manufacturing. Constr. Build. Mater. 2009, 23, 2769-2774. [CrossRef]

19. Fini, E.H.; Hajikarimi, P.; Rahi, M.; Nejad, F.M. Physiochemical, rheological, and oxidative aging characteristics of asphalt binder in the presence of mesoporous silica nanoparticles. J. Mater. Civ. Eng. 2016, 28, 04015133. [CrossRef]

20. Lushinga, N.; Cao, L.; Dong, Z. Effect of silicone oil on dispersion and low-temperature fracture performance of crumb rubber asphalt. Adv. Mater. Sci. Eng. 2019, 2019, 1-12. [CrossRef]

21. Galooyak, S.S.; Dabir, B.; Nazarbeygi, A.E.; Moeini, A. Rheological properties and storage stability of bitumen/SBS/montmorillonite composites. Constr. Build. Mater. 2010, 24, 300-307. [CrossRef]

22. Min, Y.; Akbulut, M.; Kristiansen, K.; Golan, Y.; Israelachvili, J. The role of interparticle and external forces in nanoparticle assembly. In Nanoscience and Technology: A Collection of Reviews from Nature Journals; World Scientific: Singapore, 2010; pp. 38-49.

23. Klaine, S.J.; Alvarez, P.J.; Batley, G.E.; Fernandes, T.F.; Handy, R.D.; Lyon, D.Y.; Mahendra, S.; McLaughlin, M.J.; Lead, J.R. Nanomaterials in the environment: Behavior, fate and bioavailability, and effects. Environ. Toxicol. Chem. 2008, 27, 1825-1851. [CrossRef] 
24. Boles, M.A.; Ling, D.; Hyeon, T.; Talapin, D.V. The surface science of nanocrystals. Nat. Mater. 2016, 15, 141-153. [CrossRef]

25. Hansen, C.M.; Beerbower, A. Solubility parameters. In Kirk-Othmer Encyclopedia of Chemical Technology; Wiley: New York, NY, USA, 1971; Volume 2, pp. 889-910.

26. Petosa, A.R.; Jaisi, D.P.; Quevedo, I.R.; Elimelech, M.; Tufenkji, N. Aggregation and disposition of engineered nanomaterials in aquatic environments: Role of physicochemical interactions. Environ. Sci. Technol. 2010, 44, 6532-6549. [CrossRef] [PubMed]

27. Jiangkongkho, P.; Arksornnukit, M.; Takahashi, H. The synthesis, modification, and application of nanosilica in polymethyl methacrylate denture base. Dent. Mater. 2018, 37, 582-591. [CrossRef] [PubMed]

28. Cai, L.; Shi, X.; Xue, J. Laboratory evaluation of composed modified asphalt binder and mixture containing nano-silica/rock asphalt/SBS. Constr. Build. Mater. 2018, 172, 204-211. [CrossRef]

29. Shi, X.; Cai, L.; Xu, W.; Fan, J.; Wang, X. Effects of nano-silica and rock asphalt on rheological properties of modified bitumen. Constr. Build. Mater. 2018, 161, 705-714. [CrossRef]

30. Ezzat, H.; El-Badawy, S.; Gabr, A.; Zaki, E.S.I.; Breakah, T. Evaluation of asphalt binders modified with nanoclay and nanosilica. Procedia Eng. 2016, 143, 1260-1267. [CrossRef]

31. Bala, N.; Napiah, M.; Kamaruddin, I. Effect of nanosilica particles on polypropylene polymer modified asphalt mixture performance. Case stud. Constr. Mater. 2018, 8, 447-454. [CrossRef]

32. Moghadas Nejad, F.; Zarroodi, R.; Naderi, K. Effect of Cross-linkers on the Performance of Polyethylene-modified Asphalt Binders. Proc. Inst. Civ. Eng.-Constr. Mater. 2017, 170, 186-193. [CrossRef]

33. Saltan, M.; Terzi, S.; Karahancer, S. Examination of hot mix asphalt and binder performance modified with nano silica. Constr. Build. Mater. 2017, 156, 976-984. [CrossRef]

34. Yu, R.; Fang, C.; Liu, P.; Liu, X.; Li, Y. Storage stability and rheological properties of asphalt modified with waste packaging polyethylene and organic montmorillonite. Appl. Clay Sci. 2015, 104, 1-7. [CrossRef]

35. Lazzara, G.; Milioto, S. Dispersions of nanosilica in biocompatible copolymers. Polym. Degrad. Stab. 2010, 95, 610-617. [CrossRef]

36. Yusoff, N.I.M.; Breem, A.A.S.; Alattug, H.N.; Hamim, A.; Ahmad, J. The effects of moisture susceptibility and ageing conditions on nano-silica/polymer-modified asphalt mixtures. Constr. Build. Mater. 2014, 72, 139-147. [CrossRef]

37. Daly, W.H. Relationship between Chemical Makeup of Binders and Engineering Performance; The National Academies Press: Washington, DC, USA, 2017. [CrossRef]

38. Xu, G.; Wang, H.; Zhu, H. Rheological properties and anti-aging performance of asphalt binder modified with wood lignin. Constr. Build. Mater. 2017, 151, 801-808. [CrossRef]

39. Polacco, G.; Filippi, S.; Merusi, F.; Stastna, G. A review of the fundamentals of polymer-modified asphalts: Asphalt/polymer interactions and principles of compatibility. Adv. Colloid Interface Sci. 2015, 224, 72-112. [CrossRef] [PubMed]

40. Dong, Z.-J.; Zhou, T.; Luan, H.; Williams, R.C.; Wang, P.; Leng, Z. Composite modification mechanism of blended bio-asphalt combining styrene-butadiene-styrene with crumb rubber: A sustainable and environmental-friendly solution for wastes. J. Clean. Prod. 2019, 214, 593-605. [CrossRef]

41. Rossi, C.O.; Caputo, P.; De Luca, G.; Maiuolo, L.; Eskandarsefat, S.; Sangiorgi, C. 1H-NMR spectroscopy: A possible approach to advanced bitumen characterization for industrial and paving applications. Appl. Sci. 2018, 8, 229. [CrossRef]

42. Yao, H.; You, Z.; Li, L.; Lee, C.H.; Wingard, D.; Yap, Y.K.; Shi, X.; Goh, S.W. Rheological properties and chemical bonding of asphalt modified with nanosilica. J. Mater. Civ. Eng. 2013, 25, 1619-1630. [CrossRef]

43. Soenen, H.; Redelius, P. The effect of aromatic interactions on the elasticity of bituminous binders. Rheol. Acta 2014, 53, 741-754. [CrossRef]

44. Alhamali, D.I.; Wu, J.; Liu, Q.; Hassan, N.A.; Yusoff, N.I.M.; Ali, S.I.A. Physical and rheological characteristics of polymer modified Bitumen with Nanosilica particles. Arab. J. Sci. Eng. 2015, 41, 1521-1530. [CrossRef]

45. Santagata, E.; Baglieri, O.; Tsantilis, L.; Dalmazzo, D. Rheological characterization of bituminous binders modified with carbon nanotubes. Procedia-Soc. Behav. Sci. 2012, 53, 546-555. [CrossRef] 
46. Lushinga, N.; Cao, L.; Dong, Z.; Yang, C.; Assogba, C.O. Performance evaluation of crumb rubber asphalt modified with silicone-Based warm mix additives. Adv. Civ. Eng. 2020, 2020, 1-17. [CrossRef]

47. Sabaraya, I.V.; Filonzi, A.; Hajj, R.; Das, D.; Saleh, N.B.; Bhasin, A. Ability of nanomaterials to effectively disperse in asphalt binders for use as a modifier. J. Mater. Civ. Eng. 2018, 30, 04018166. [CrossRef]

Publisher's Note: MDPI stays neutral with regard to jurisdictional claims in published maps and institutional affiliations.

(C) 2020 by the authors. Licensee MDPI, Basel, Switzerland. This article is an open access article distributed under the terms and conditions of the Creative Commons Attribution (CC BY) license (http://creativecommons.org/licenses/by/4.0/). 